\title{
Pro Properties, Contra Generalized Kinds
}

\author{
Veerle Van Geenhoven \\ Max Planck Institut, Nijmegen
}

\section{Introduction}

In Carlson (1977), English bare plurals are treated as unambiguously kind-denoting expressions. For example, although in (1) horses receives a quasi-universal interpretation, Carlson argues that this bare plural denotes a kind. And although in (2) horses receives an existential interpretation, this bare plural is said to denote a kind as well.

Horses are shy.

(2) Horses were galloping in the meadow.

People have criticized Carlson's proposal for a number of reasons, most of which are summarized in Krifka et al. (1995). One of the objections is that English bare plurals have indefinite interpretations. In (3), we see that the bare plural horses can occur as the argument of the existential predicate. (4) shows that the singular indefinite $a$ horse can occur in such a context as well. However, other expressions which can denote a kind, such as the NP the horse in (5), cannot be the argument of the existential predicate. This is shown in (6). On Carlson's theory, we would expect that kind-denoting expressions have the same distribution.

(3) There are horses stampeding through the gate.

(4) There is a horse stampeding through the gate.

(5) The horse is a mammal.

(6) * There is the horse stampeding through the gate.

Building on this observation and on McNally's (1992) view that the argument of the existential predicate is a property, I proposed in Van Geenhoven (1998) that narrow scope indefinites or, in general, weak nominals are property-denoting expressions. Thus, on their narrow scope reading a horse in (7) and horses in (8) denote properties.

(7) Sam didn't buy a borse.

i. "It is not the case that Sam bought any horse." $\quad(<s,<e, t\rangle)$

ii. "There was a horse such that Sam did not buy it."

(8) Sam didn't buy horses.

i. "It is not the case that Sam bought any horses." $\quad(<s,\langle e, \downarrow>)$

ii. \# "There were some horses such that Sam did not buy them."

Chierchia (1998) has presented a number of objections to a property interpretation of English bare plural arguments. According to Chierchia, "an approach along these lines leaves us completely in the dark as to why in languages like English we find bare plurals and bare mass nouns but not bare singular count nouns [Chierchia (1998): 366]." Moreover, it gives no way of treating reflexive kind anaphora, and it does not give a way of treating the scopelessness of the English bare plural.

This paper has two goals. The first goal is to answer the above objections and to point out problems in the generalized kinds theory of bare nominals as 
presented in Chierchia (1998). The second goal is to show that a property-based analysis of the English bare plural in existential contexts can be extended towards a uniform account of a wide range of narrow scope phenomena. This is something that a kind-based account does not allow for.

The paper is organized as follows. In section 2 , I briefly summarize what it buys semanticists to allow property arguments. Section 3 gives a short review of the basic ideas of a kind-based theory of bare nominals and answers the criticisms of a property-based account as raised in Chierchia (1998). In section 4, I show that a. property analysis provides a uniform account of (inherent) narrow scope. Section 5 concludes the paper.

\section{Property arguments}

Since Williams (1983) and Partee (1987) it has been widely agreed that propertydenoting NPs (type $\langle s,\langle e, t>>$ ) occur in predicative positions. Thus, the NP $a$ student in (9) and a fool in (10) each denote a property.

John is a student.

John considers Bill $a$ fool.

Zimmermann (1993) argued that property-denoting NPs can also occur in argument positions in order to account for the opaque interpretation of indefinite complements of verbs like look for.

(11) Sam was looking for a unicorn.

i. "Sam was looking for any unicorn" $\quad(<s,<e, \downarrow>)$

ii. "There was a unicorn such that Sam was looking for it."

In Van Geenhoven (1998), I argued that allowing verbs to combine with property arguments could account for nonspecificity in general. This leads to the view that verbs like buy can combine with a property-denoting argument or with an individual-denoting or quantifier-denoting argument. This is illustrated in (12) and (13). If a verb takes a property-denoting argument, like in (12), I call this semantic incorporation. $^{1}$

$$
\begin{aligned}
& \forall \mathbf{x} \forall \mathrm{P} \forall \mathrm{w} \square\left(\text { buy }_{\mathrm{w}}(\mathbf{x}, \mathrm{P}) \rightarrow \exists \mathrm{y}\left[\operatorname{acquire}_{\mathrm{w}}(\mathbf{x}, \mathrm{y}) \wedge \mathrm{P}_{\mathrm{w}}(\mathrm{y})\right]\right) \\
& \forall \mathbf{x} \forall \mathrm{y} \forall \mathrm{w} \square\left(\text { buy }_{\mathrm{w}}(\mathbf{x}, \mathrm{y}) \rightarrow \text { acquire }_{\mathrm{w}}(\mathbf{x}, \mathrm{y})\right)
\end{aligned}
$$

The idea that a verb can contribute the existential interpretation of one of its arguments is borrowed from Carlson (1977). The major advantage of this idea is that it provides a straightforward account for narrow scope: Every operator which takes a semantically incorporating verb in its scope will automatically take its existentially bound argument into its scope as well. The narrow scope reading of $a$ horse in (7), repeated here as (14), follows from the assumption that on its nonspecific interpretation a singular indefinite denotes a property. ${ }^{2}$

(14) Sam didn't buy a horse.

i. "It is not the case that Sam bought a horse."

ii. "There was a horse such that Sam did not buy it."

$(<s,<e, t>>)$

Moreover, if in existential contexts a nominal expression is inherently propertydenoting, its inherent narrow scope is predicted as well. Assuming that the English 
bare plural is such a case, I account for the inherent narrowness of the bare plural, as illustrated in (8) and repeated here as (15), by concluding that in this episodic context the bare plural horses can only be an argument of a semantically incorporating verb.

Sam didn't buy horses.

i. "It is not the case that Sam bought any horses." $\quad(\langle s,\langle e, \downarrow\rangle)$

ii. \# "There were some horses such that Sam did not buy them."

\section{Kind arguments}

Chierchia (1998) proposes that in general bare nominals only appear in verbal argument positions if they denote a kind. In the lexicon, mass nouns denote kinds. So they can appear as arguments without any problem (e.g. milk in There was milk in the fridge). In contrast, singular count nouns are predicates of singularities, and plural count nouns are predicates of pluralities. This is illustrated for $d o g$ and $d o g s$ in (16a) and (16b) assuming that Joeri, Reba, and Dimmi are all the dogs in the world. ${ }^{3}$

$$
\begin{aligned}
& \text { a. } \llbracket \operatorname{dog}_{\mathrm{CN}-\mathrm{sg}} \rrbracket=\left[\begin{array}{lll}
\text { joeri } & \text { reba } & \text { dimmi }
\end{array}\right] \\
& \text { b. } \llbracket \operatorname{dog}_{\mathrm{CN}-\mathrm{pl}} \rrbracket=\left[\begin{array}{c}
\text { joeri, reba }\} \\
\{\text { reba, dimmi }\}\{\text { joeri, dimmi }\} \\
\{\text { joeri, reba, dimmi }\}
\end{array}\right]
\end{aligned}
$$

In Chierchia's account, the cap operator $\cap$ turns the predicate expressed by a plural count noun into a kind-denoting argument. In this way, bare plurals can be the argument of individual-level predicates. This illustrated for dogs in (17a) in (17b).
a. Dogs are intelligent.
b. intelligent $(\cap$ dogs $)$

To account for the existential interpretation of English bare plurals, as dogs in (18), an existential quantifier comes in on demand. For this purpose, Chierchia defines the mechanism of so-called Derived Kind Predication (DKP) which enables kinddenoting expressions to combine with object-level predicates.

(18) Dogs are ruining my garden.

\section{DERIVED KIND PREDICATION (DKP)}

If $P$ applies to objects and $k$ denotes a kind, then $P(k) \equiv \exists x[\cup k(x) \wedge P(x)]$

In DKP, the cup operator $\cup$ derives properties from kinds. This is illustrated for dogs in (18) in (20).

$$
\begin{aligned}
\text { Dogs are ruining my garden } & \Rightarrow \text { ruining-my-garden }(\cap \operatorname{dogs}) \\
& \equiv \exists x[\cup \cap \operatorname{dogs}(x) \wedge \text { ruining-my-garden }(x)]
\end{aligned}
$$

Note that in this neo-Carlsonian account, the inherent narrow scope of the bare plural in (15) is derived from the fact that a bare plural denotes a kind whose existential interpretation is contributed by an external source, namely DKP. Whenever this external source is in the scope of some operator, the existentially 
bound instance of the kind denoted by a bare plural will be in the scope of that operator as well.

It is assumed that $\cap$, the operator which turns a property into its corresponding kind, does not apply to properties that hold of singularities. This then explains why English bare count singulars are out and why (21) is ungrammatical.

* Dog walked.

The ungrammaticality of (21) brings us to the first objection Chierchia raised for a property-based approach. ${ }^{4}$

\subsection{Are English bare singulars a problem for a property analysis?}

According to Chierchia, if a verb can combine with a property argument this incorrectly predicts that English has bare count singulars since bare count singulars denote properties. Hence, (21) should be grammatical. My reply in short will be that it is not a task for a combinatoric mechanism like semantic incorporation to explain why in English bare singular count phrases are out. First, I want to point out two problems for a neo-Carlsonian account of the ungrammaticality of (21).

Chierchia's account is based upon two assumptions. One assumption is that singular count nouns are predicates of singular entities, and the other that plural count nouns are predicates of plural entities. This was shown for dog and dogs in (16a) and (16b). However, both assumptions are problematic. First, the claim that bare lexical stems are predicates of singularities cannot hold crosslinguistically. This is shown by the Inuit example in (22), in which we have the incorporated bare stem for "dog". This bare stem, qimmi-, can very well be understood as a predicate of either a singular or a plural entity, namely as "a dog" or as "sm dogs".

$$
\begin{aligned}
& \text { Angut qimmi-qar-p-u-q. } \\
& \text { man.ABS.SG dog-have-IND-[-tr]-3SG } \\
& \text { "The man has a dog/sm dogs." }
\end{aligned}
$$

(Inuit)

Also English compounding provides evidence for the claim that the singular/plural distinction cannot be regarded as a distinctive feature of the bare lexical stem of a count noun. Consider for example dog food in (23).

$$
\begin{aligned}
& \text { dog food " } \\
& \text { "food for one or more dogs" }
\end{aligned}
$$

The paraphrase under (23) shows that $d o g$ in $d o g$ food receives a count interpretation. The paraphrase makes also clear that it is underdetermined whether $d o g$ is a predicate which holds of a singular dog or of a plurality of dogs.

The second problem is this: The claim that bare plurals are predicates of pluralities is wrong for English. If it were true that bare plurals can only be predicates of pluralities one would expect that B's answer in the dialogue in (24) is felicitous if B has only one dog. However it is not. ${ }^{5}$

$$
\text { A : Do you have dogs? B (who has one dog) : \# No, I don't. }
$$

This leads me to conclude that the reason why English lacks bare count singulars cannot be that $\cap$ applies to dogs but not to dog since (22), (23), and (24) seem to 
indicate that the common noun $d o g$ and the bare plural phrase dogs have the same meaning. That is, they denote properties that hold of singularities and of pluralities. This is illustrated in (25) and (26).

$$
\begin{aligned}
& \llbracket \operatorname{dog}_{C N} \rrbracket=\left[\begin{array}{c}
\text { joeri } \quad \text { reba dimmi } \\
\{\text { joeri, reba }\}\{\text { reba, dimmi }\}\{\text { joeri, dimmi }\} \\
\{\text { joeri, reba, dimmi }\}
\end{array}\right] \\
& \llbracket[\mathrm{dog}-\mathrm{s}]_{\mathrm{CNP}} \rrbracket=\left[\begin{array}{c}
\text { joeri } \mathrm{\text {reba }} \text { dimmi } \\
\{\text { joeri, reba }\}\{\text { reba, dimmi }\}\{\text { joeri, dimmi }\} \\
\{\text { joeri, reba, dimmi }\}
\end{array}\right]
\end{aligned}
$$

Turming back to Chierchia's objection that a property-based approach does not account for why English lacks bare count singulars, it seems to me that we should not look for any deep semantic explanation of this fact. Indeed, it can be shown that the ungrammaticality of bare count singular NPs is an idiosyncratic property of English (and maybe of other languages as well). This is illustrated by the Inuit example (27) which contains the bare count singular qimmeq. Qimmeq means "a dog" or "the dog" and is perfectly grammatical.

$$
\begin{array}{lcl}
\text { Juuna-p } & \text { qimme-q } & \text { tuqut-p-a-a. } \\
\text { J.-ERG } & \text { dog-SG.ABS } & \text { kill-IND-[+tr]-3SG3SG } \\
\text { "John killed a/the dog." } &
\end{array}
$$

Thus I will assume that in English there is some syntactic constraint that disallows to project count nouns onto bare singular phrases.

\subsection{Is reflexive kind anaphora a problem for a property analysis?}

The second objection that Chierchia (1998) raises to a property-based account of the English bare plural is that it cannot account for reflexive kind anaphora in an adequate way. If a verbal predicate is responsible for introducing the existential interpretation of the bare plural, as I am assuming and as Carlson (1977) assumed, then we cannot account for the ambiguity of (28).

Dogs were biting themselves.

i. "Each dog was biting itself."

ii. "Dogs were biting dogs."

(object-oriented)

(kind-oriented)

In Chierchia's kind-based account, the ambiguity of (28) is treated in terms of whether DKP applies before or after $\lambda$-application. This is illustrated in (28').

$\left(28^{\prime}\right)$ i. dogs were biting themselves

$\Rightarrow \lambda \mathbf{x}_{\mathrm{O}}\left[\right.$ bite $\left.\left(\mathrm{x}_{\mathrm{O}}, \mathrm{x}_{\mathrm{O}}\right)\right](\cap$ dogs $)$

$\equiv \exists \mathbf{x}_{\mathrm{O}}\left[\cup \cap \operatorname{dogs}(\mathbf{x}) \wedge \operatorname{bite}\left(\mathbf{x}_{\mathrm{O}}, \dot{x}_{\mathrm{O}}\right)\right]$

ii. dogs were biting themselves

$\Rightarrow \lambda \mathbf{x}_{\mathrm{k}}\left[\mathbf{b i t e}\left(\mathrm{x}_{\mathrm{k}}, \mathbf{x}_{\mathrm{k}}\right)\right](\cap$ dogs $)$

$\equiv \operatorname{bite}(\cap$ dogs, $\cap$ dogs $)$

$\equiv \exists \mathrm{x}_{\mathrm{o}} \exists \mathrm{y}_{\mathrm{o}}\left[\cup \cap \operatorname{dogs}\left(\mathrm{x}_{\mathrm{o}}\right) \wedge \cup \cap \operatorname{dogs}\left(\mathrm{y}_{\mathrm{o}}\right) \wedge \operatorname{bite}\left(\mathrm{x}_{\mathrm{o}}, \mathrm{y}_{\mathrm{o}}\right)\right]$ 
However, this procedural explanation has a problem. We saw before in (19) that DKP is definited as a rule which applies if there is a particular type mismatch when a verb combines with its arguments. In (28'i), there is a clear type mismatch: bite is interpreted as a relation between object individuals and the bare plural subject dogs delivers a kind. However, in (28'ii), there is no type mismatch after the arguments have been saturated since like in (28'i) the reflexive pronoun themselves determines the sort of both arguments of bite, namely, they are sorted as variables of kind individuals $x_{k}$. So why should DKP apply? What DKP is apparently allowed to do in (28'ii) is to reset the sort of an already saturated argument, a resetting for which no other reason exists than that in the end bite is understood as a relation between two objects. But if bite must be understood that way, why can themselves determine the sort of the arguments of bite as kinds to begin with? In the remainder of this section, I sketch a property-based account of the ambiguity of (28) in which bite is unambiguously interpreted as a relation between objects and no sortal resetting is required.

(29) gives the two translations of the reflexive pronoun themselves. On its interpretation as an object anaphor, themselves identifies the object denoted by the internal argument of a standard transitive verb with the object denoted by the external argument of this verb. This is captured in (29i). On its kind interpretation, themselves identifies the kind to which the internal argument of a semantically incorporating verb belongs, with the kind to which this verb's external argument belongs. This is captured in (29ii).

$$
\text { i. } \quad \text { themselves } \Rightarrow \lambda R \lambda w \lambda x \exists y[R(x, y) \wedge y=x]
$$

where $\mathrm{R}$ is a variable of type $\langle s,\langle e,\langle e, t\rangle\rangle\rangle$

ii. themselves $\Rightarrow \lambda \Re \lambda w \lambda x \exists P\left[\Re(P)(x) \wedge \cap P=\cap Q^{x}\right]$

where $\mathfrak{R}$ is a variable of type $\langle<s,\langle e, t\rangle\rangle,\langle s,\langle e, t\rangle\rangle>$ and

$\cap^{\mathrm{x}}$ is a pronominal variable which stands for the kind $\cap \mathrm{Q}$ to which $\mathrm{x}$ belongs

Note that unlike in (28i) and (28ii), where in both cases the anaphoric internal argument themselves determines the sort of both verbal arguments, that is, as object individuals $x_{o}$ or as kind individuals $x_{k}$, I separate the resolution of the anaphoric internal argument themselves from the determination of the sort of the verb's arguments.

(30i) gives the standard translation of bite as a relation between two individuals, and (30ii) gives the semantically incorporating version of the relation expressed by bite. (31) gives the translation of the subject dogs as a property of being one or more dogs.

$$
\begin{aligned}
& \text { i. } \quad \text { bite } \Rightarrow \lambda w \lambda y \lambda x\left[\text { bite }_{w}(x, y)\right] \\
& \text { ii. } \quad \text { bite } \Rightarrow \lambda P \lambda w \lambda x \exists y\left[b i t e_{w}(x, y) \wedge P_{w}(y)\right] \\
& \text { dogs } \Rightarrow \lambda w \lambda y\left[\operatorname{dogs}_{w}(y)\right]
\end{aligned}
$$

To derive the object-oriented reading of (28), themselves in (29i) is first combined with bite in (30i) yielding (32).

$$
\begin{aligned}
& \text { were biting themselves } \\
& \Rightarrow \lambda \mathrm{R} \lambda \mathrm{w} \lambda \mathrm{x} \exists \mathrm{y}[\mathrm{R}(\mathrm{x}, \mathrm{y}) \wedge \mathrm{y}=\mathrm{x}]\left(\lambda \mathrm{w} \lambda \mathrm{y} \lambda \mathrm{x}\left[\text { bite }_{\mathrm{w}}(\mathrm{x}, \mathrm{y})\right]\right) \\
& \equiv \lambda \mathrm{w} \lambda \mathrm{x} \exists \mathrm{y}\left[\mathrm{bite}_{\mathrm{w}}(\mathrm{x}, \mathrm{y}) \wedge \mathrm{y}=\mathrm{x}\right] \\
& \equiv \lambda \mathrm{w} \lambda \mathrm{x}\left[\mathrm{bite}_{\mathrm{w}}(\mathrm{x}, \mathrm{x})\right]
\end{aligned}
$$


As a next step, shown in (33), the VP were biting themselves is lifted to a semantically incorporating expression so that this VP can combine with the property-denoting subject dogs, as illustrated in (34):

$$
\begin{aligned}
& \text { were biting themselves } \Rightarrow \lambda \mathrm{P} \lambda \mathrm{w} \exists \mathbf{x}\left[\text { bite }_{\mathrm{w}}(\mathrm{x}, \mathrm{x}) \wedge \mathrm{P}_{\mathrm{w}}(\mathrm{x})\right] \\
& \text { dogs were biting themselves } \\
& \Rightarrow \quad \lambda \mathrm{P} \lambda \mathrm{w} \exists \mathbf{x}\left[\text { bite }_{\mathrm{w}}(\mathrm{x}, \mathrm{x}) \wedge \mathrm{P}_{\mathrm{w}}(\mathrm{x})\right]\left(\lambda \mathrm{w} \lambda \mathrm{y}\left[\operatorname{dogs}_{\mathrm{w}}(\mathrm{y})\right]\right) \\
& \equiv \lambda \mathrm{w} \exists \mathbf{x}\left[\text { bite }_{\mathrm{w}}(\mathbf{x}, \mathbf{x}) \wedge \operatorname{dogs}_{\mathrm{w}}(\mathbf{x})\right]
\end{aligned}
$$

To derive the kind-oriented reading of (28), themselves in (29ii) is first combined with bite as the semantically incorporating verb shown in (30ii). This then gives us (35).

$$
\begin{aligned}
& \text { were biting themselves } \\
& \Rightarrow \lambda \Re \lambda \mathrm{w} \lambda \mathbf{x} \exists \mathrm{P}\left[\Re(\mathrm{P})(\mathrm{x}) \wedge \cap \mathrm{P}=\cap \mathrm{Q}^{\mathrm{x}}\right]\left(\lambda \mathrm{P} \lambda \mathrm{w} \lambda \mathbf{x} \exists \mathrm{y}\left[\text { bite }_{\mathrm{w}}(\mathrm{x}, \mathrm{y}) \wedge \mathrm{P}(\mathrm{y})\right]\right) \\
& \equiv \lambda \mathrm{w} \lambda \mathrm{x} \exists \mathrm{P} \exists \mathrm{y}\left[\mathrm{bite}_{\mathrm{w}}(\mathrm{x}, \mathrm{y}) \wedge \mathrm{P}(\mathrm{y}) \wedge \cap \mathrm{P}=\cap \mathrm{Q}^{\mathrm{x}}\right]
\end{aligned}
$$

In a next step, shown in (36), the VP were biting themselves is lifted to a semantically incorporating expression so that this VP can combine with the property-denoting subject dogs. This is shown in (37), which represents the last step in the derivation of the kind-oriented reading of (28).

$$
\begin{aligned}
& \text { were biting themselves } \\
& \Rightarrow \quad \lambda Q \lambda w \exists x \exists P \exists y\left[b^{2} e_{w}(x, y) \wedge P(y) \wedge \cap P=\cap Q^{x} \wedge Q(x)\right] \\
& \text { dogs were biting themselves } \\
& \Rightarrow \lambda Q \lambda w \exists x \exists P \exists y\left[b^{2} e_{w}(x, y) \wedge P_{w}(y) \wedge \cap P=\cap Q^{x} \wedge Q_{w}(x)\right] \\
& \left(\lambda \mathrm{w} \lambda \mathrm{y}\left[\operatorname{dogs}_{\mathrm{w}}(\mathrm{y})\right]\right) \\
& \equiv \lambda \mathrm{w} \exists \mathrm{x} \exists \mathrm{P} \exists \mathrm{y}\left[\text { bite }_{\mathrm{w}}(\mathrm{x}, \mathrm{y}) \wedge \mathrm{P}_{\mathrm{w}}(\mathrm{y}) \wedge \cap \mathrm{P}=\cap \mathrm{Q}^{\mathrm{x}} \wedge \operatorname{dogs}_{\mathrm{w}}(\mathrm{x})\right] \\
& \equiv \lambda \mathrm{w} \exists \mathrm{x} \exists \mathrm{P} \exists \mathrm{y}\left[\mathrm{bite}_{\mathrm{w}}(\mathrm{x}, \mathrm{y}) \wedge \mathrm{P}_{\mathrm{w}}(\mathrm{y}) \wedge \cap \mathrm{P}=\cap \operatorname{dogs}^{\mathrm{x}} \wedge \operatorname{dogs}_{\mathrm{w}}(\mathrm{x})\right] \\
& =\lambda \mathrm{w} \exists \mathrm{x} \exists \mathrm{y}\left[\operatorname{bite}_{\mathrm{w}}(\mathrm{x}, \mathrm{y}) \wedge \operatorname{dog}_{\mathrm{w}}(\mathrm{y}) \wedge \operatorname{dog}_{\mathrm{w}}(\mathrm{x})\right]
\end{aligned}
$$

In the third line of (37), we see that the kind anaphora resolution instruction still needs to be carried out. For this purpose, I assume that the cap operator $\cap$ creates out of every property that holds both of singularities and of pluralities its corresponding kind. ${ }^{7}$ This kind then serves as the antecedent of themselves, as illustrated in the previous last line of (37). Note that unlike a kind-based account we do not need an extra rule of existential interpretation to arrive at the correct representation of the kind-oriented reading of (28) nor must we manipulate the sort of the verb's arguments.

\subsection{Is the bare plural's scopelessness a problem for a property analysis?}

The third and last objection Chierchia (1998) raises to a property-based analysis of the English bare plural is that it cannot explain the scopelessness of the latter. As I said before, in order to account for the narrow scope readings of the singular indefinite a horse in (38) and of the bare plural horses in (39) I propose that on these readings they both denote a property. Unlike the singular indefinite, the bare plural receives only a narrow interpretation since in existential contexts it is unambiguously property-denoting. 
(38) Sam didn't buy a horse.

i. "It is not the case that Sam bought any horse." $\quad(\langle\mathrm{s},\langle e, \downarrow\rangle)$

ii. "There was a horse such that Sam did not buy it."

(39) Sam didn't buy horses.

i. "It is not the case that Sam bought any horses." $\quad(\langle\mathrm{s},\langle e, \downarrow\rangle)$

ii. \# "There were some horses such that Sam did not buy them."

However, if we derive the narrow scope of singular indefinites and bare plurals in one and the same way, it seems that we predict that like bare plurals singular indefinites can take narrow scope with respect to for-adverbials. (40) seems to show that this is an incorrect prediction. The sentence Bill discovered a flea on his dog for an hour can only have the crazy reading that the same flea was discovered again and again throughout the hour. (41) instead does not have such a crazy reading.

(40) ? Bill discovered a flea on his dog for an hour.

(41) Bill discovered fleas on his dog for an hour.

First of all, it has been debated in the literature whether the contrast between (40) and (41) must be accounted for in terms of scope. The major disadvantage of a scope account is that it must stipulate that singular indefinites take wide scope with respect to a for-adverbial. For this reason, nonscope accounts have been given as for instance in Krifka (1989) and Zucchi and White (1996). According to Krifka, for-adverbials come with a condition on the event predicate they combine with, namely, they require that the event predicate they combine with be atelic or nonquantized. In the remainder of this section, I sketch an alternative and propertybased condition-on-the-event-predicate approach in which iterativity plays a crucial role. ${ }^{8}$

First, in Van Geenhoven (2000) I point out that transitive verbs give rise to what I call "iterative weak" and "iterative strong" readings. For example, if a transitive verb like dial has an indefinite complement, as in (42), the only available reading is the iterative strong reading, that is, the reading in which a particular number is dialed again and again. If the same transitive verb dial takes a bare plural complement, as in (43), the only available reading is the iterative weak reading, that is, the reading in which Sam dials and dials wrong numbers again and again.

Sam dialed a wrong number for an hour.

i. \# "Sam dialed a wrong number again and again for an hour." \# iter. weak

ii. "There was a wrong number and Sam dialed it again and again for an hour."

iterative strong

(43) Sam dialed wrong numbers for an hour.

i. "Sam dialed one or more wrong numbers again and again for an hour." iterative weak

ii. \# "There were some wrong numbers and Sam dialed them again and again for an hour."

\# iterative strong

Second, with this observation in mind I suggest that one must explain the oddness of (40), repeated below as (44), by comparing it with (42), that is, one must answer the question of why the interaction of an indefinite with a for-adverbial sounds odd in (44) but not in (42). One must ask that question rather than the question that has been asked so far, namely, the question of why the interaction of 
an indefinite with a for-adverbial sometimes sounds odd whereas the interaction of a bare plural with a for-adverbial never sounds odd, as illustrated by (43) and (45).

? Bill discovered a flea on his dog for an hour.

i. \# "Bill discovered a flea again and again for an hour." \# iterative weak

ii. ? "There was a flea and Bill discovered it again and again for an hour."

Bill discovered fleas on his dog for an hour.

? iterative strong

i. "Bill discovered one or more fleas again and again for an hour." it. weak

ii. \# "There were some fleas and Bill discovered them again and again for an hour."

\# iterative strong

Third, the idea upon which my alternative condition-on-the-event-predicate approach relies, is that a for-adverbial simply describes the duration of the event time of the event predicate with which it combines. This is for instance the case with the predicate torture a rabbit in Bill tortured a rabbit for an hour or watch a humming-bird in Tom watched a humming-bird for a while. If the described event cannot last the duration expressed by a for-adverbial, the event predicate itself is understood in an iterative way. This iterative interpretation can be triggered by an overt iterative expression like every day in Bill discovered a flea on his dog every day for a month. But iterativity can also be implicitly present in the interpretation of the verb. For instance dial a number for an hour almost automatically means to dial a number again and again for an hour since dialing a number normally never takes an hour. For the purpose of this paper I cannot explain in detail how exactly iterativity is expressed in the verb. But the following examples of silent iterativity in the verbs dial and discover should make the idea a bit more concrete. ${ }^{9}$

To get the iterative weak interpretation of (43), the verb dial is translated as the property-taking and implicitly iterative verb (46).

$$
\begin{aligned}
& \operatorname{dial} \Rightarrow \lambda \mathrm{P} \lambda \mathrm{t} \lambda \mathrm{x} \exists \mathrm{y}\left(\operatorname{AGAIN} \operatorname{dial}^{*}(\mathrm{x}, \mathrm{y}) \text { at } \mathrm{t} \wedge \mathrm{P}(\mathrm{y})\right) \\
& \text { where } \\
& \operatorname{AGAIN~dial} *(\mathrm{x}, \mathrm{y}) \text { at } \mathrm{t}=1 \text { iff } \\
& \forall \mathrm{t}^{\prime}\left(\mathrm{t}^{\prime} \subset \mathrm{t} \rightarrow \operatorname{AGAIN} \exists \mathrm{y}^{\prime}\left(\mathrm{y}^{\prime} \subset \mathrm{y} \wedge \operatorname{dial}\left(\mathrm{x}, \mathrm{y}^{\prime}\right) \text { at } \mathrm{t}^{\prime}\right)\right) \\
& \text { where } \\
& \operatorname{AGAIN} \exists y^{\prime}\left(y^{\prime} \subset y \wedge \operatorname{dial}\left(x, y^{\prime}\right) \text { at } t^{\prime}\right)=1 \text { iff } \exists y^{\prime}\left(y^{\prime} \subset y \wedge \operatorname{dial}\left(x, y^{\prime}\right) \text { at } t^{\prime}\right)=1 \\
& \text { and AGAIN } \exists y^{\prime}\left(y^{\prime} \subset y \wedge \operatorname{dial}\left(x, y^{\prime}\right) \text { at } t^{\prime}\right) \text { is defined } \\
& \text { AGAIN } \exists y^{\prime}\left(y^{\prime} \subset y \wedge \operatorname{dial}\left(x, y^{\prime}\right) \text { at } t^{\prime}\right) \text { is defined iff } \\
& \exists t^{\prime \prime}\left(\operatorname{MAX}\left(\lambda t \exists y^{\prime \prime}\left(y^{\prime} \subset y \wedge \operatorname{dial}\left(x, y^{\prime}\right) \text { at } t\right)\right)\left(t^{\prime \prime}\right) \wedge t^{\prime \prime}<t^{\prime}\right. \text { and } \\
& \text { where }
\end{aligned}
$$

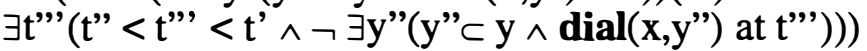

$$
\begin{aligned}
& \operatorname{MAX}\left(\lambda \mathrm{t} \exists \mathrm{y}^{\prime}\left(\mathrm{y}^{\prime} \subset \mathrm{y} \wedge \operatorname{dial}(\mathrm{x}, \mathrm{y}) \text { at } \mathrm{t}\right)\right)\left(\mathrm{t}^{\prime \prime}\right)=1 \text { iff } \\
& \exists y^{\prime}\left(y^{\prime} \subset y \wedge \operatorname{dial}\left(x, y^{\prime}\right) \text { at } t^{\prime \prime}\right)=1 \text { and } \neg \exists t\left(\operatorname{dial}\left(x, y^{\prime}\right) \text { at } t \wedge t^{\prime \prime} \subset t\right)
\end{aligned}
$$

The star operator on "AGAIN dial" does the same distributing job as Link's (1983) star operator on nominal predicates in that it distributes events of a particular kind and also the events' participants over event times. The AGAIN operator brings along two meaning components. The first component is that when applied to an event description, it states that an event of the same kind has taken place before. Hence, (46) says that for each event time at which a dialing takes place there is a maximal preceding dialing time. The second meaning contribution of AGAIN is that between two events of the same kind an interval must exist at which no event of the same kind takes place. (46) therefore says that there must be a hiatus between two 
dialings. ${ }^{10}$ Adopting (46) as the translation of dial in the iterative weak reading of (43), as shown in (43'), we see that the property denoted by the bare plural wrong numbers is distributed over dialing times. Note in this respect that I regard the bare plural as denoting a property that can hold of singularities and of pluralities (see (26)). This makes wrong numbers a temporally distributable property.

(43') Sam dialed wrong numbers for an hour

$$
\begin{aligned}
& \Rightarrow \exists \mathrm{t}\left[1-\operatorname{hour}(\mathrm{t}) \wedge \exists \mathrm{y}\left(\operatorname{AGAIN} \operatorname{dial}^{*}(\mathrm{~s}, \mathrm{y}) \text { at } \mathrm{t} \wedge \text { wrong-numbers }(\mathrm{y})\right)\right. \\
& \equiv \exists \mathrm{t}\left[\mathbf { 1 - h o u r } ( \mathrm { t } ) \wedge \exists \mathrm { y } \text { (wrong-numbers } ( \mathrm { y } ) \wedge \forall \mathrm { t } ^ { \prime } \left(\mathrm { t } ^ { \prime } \subset \mathrm { t } \rightarrow \exists \mathrm { t } ^ { \prime \prime } \exists \mathrm { y } ^ { \prime } \left(\mathrm{y}^{\prime} \subset \mathrm{y} \wedge\right.\right.\right. \\
& \operatorname{dial}\left(s, y^{\prime}\right) \text { at } t^{\prime} \wedge \operatorname{MAX}\left(\lambda t \exists y ^ { \prime } \left(y^{\prime} \subset y \wedge \operatorname{dial}\left(s, y^{\prime}\right) \text { at } t \wedge\right.\right. \\
& \text { wrong-numbers(y") at } t))\left(t^{\prime \prime}\right) \wedge t \text { " }<t^{\prime} \wedge \exists t \text { ' }\left(t^{\prime \prime}<t^{\prime \prime} "<t^{\prime} \wedge\right. \\
& \neg \exists \text { y"(y" } \subset \mathrm{y} \wedge \operatorname{dial}(\mathrm{s}, \mathrm{y} ") \text { at } \mathrm{t} " \prime))))]
\end{aligned}
$$

Unlike (43), (42) lacks an iterative weak interpretation since the singular indefinite $a$ wrong number cannot be semantically incorporated by the verb dial in (46). $A$ wrong number denotes a property that only holds of singularities and as such it does not provide a temporally distributable property.

Similarly, to get the iterative weak interpretation of (45) as in (45'), the verb discover is translated as the property-taking and implicitly iterative verb (47).

$$
\begin{aligned}
& \text { discover } \Rightarrow \lambda \mathrm{P} \lambda \mathrm{t} \lambda \mathrm{x} \quad \exists \mathrm{y}(\operatorname{AGAIN} \text { discover* }(\mathrm{x}, \mathrm{y}) \text { at } \mathrm{t} \wedge \mathrm{P}(\mathrm{y})) \\
& \text { Bill discovered fleas (on his dog) for an hour } \\
& \Rightarrow \quad \exists \mathrm{t}[\mathbf{1 - h o u r}(\mathrm{t}) \wedge \exists \mathrm{y}(\operatorname{AGAIN} \operatorname{discover} *(\mathrm{~b}, \mathrm{y}) \text { at } \mathrm{t} \wedge \text { fleas }(\mathrm{y})) \\
& \equiv \exists \mathrm{t}\left[1-\operatorname{hour}(\mathrm{t}) \wedge \exists \mathrm{y}\left(\text { fleas } ( \mathrm { y } ) \wedge \forall \mathrm { t } ^ { \prime } \left(\mathrm { t } ^ { \prime } \subset \mathrm { t } \rightarrow \exists \mathrm { t } ^ { \prime \prime } \exists \mathrm { y } ^ { \prime } \left(\mathrm{y}^{\prime} \subset \mathrm{y} \wedge\right.\right.\right.\right. \\
& \text { discover }\left(b, y^{\prime}\right) \text { at } t^{\prime} \wedge \operatorname{MAX}\left(\lambda t \quad \exists y ^ { \prime } \left(y^{\prime} \subset y \wedge \operatorname{discover}\left(b, y^{\prime}\right) \text { at } t \wedge\right.\right.
\end{aligned}
$$

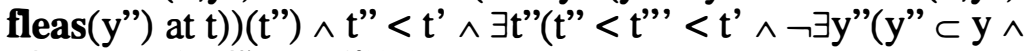

$$
\begin{aligned}
& \text { discover(b,y") at } \left.\left.\left.t^{\prime \prime \prime}\right)\right)\right) \text { )] }
\end{aligned}
$$

Unlike (45), (44) lacks an iterative weak interpretation since the singular indefinite $a$ flea cannot be semantically incorporated by the verb discover in (47). The reason is that a flea does not provide a temporally distributable property.

Whereas we make use of semantically incorporating verbs to account for iterative weak readings, I propose that to account for iterative strong readings we make use of nonincorporating verbs. For example, to arrive at the iterative strong reading of (42) the nonincorporating iterative version of dial in (48) is used.

$$
\begin{aligned}
& \operatorname{dial} \Rightarrow \lambda y \lambda t \lambda x\left(\operatorname{AgAIN}^{*} \operatorname{dial}(x, y) \text { at } t\right) \\
& \text { where } \\
& \text { AGAIN* dial }^{*}(x, y) \text { at } \mathrm{t}=1 \text { iff } \forall \mathrm{t}^{\prime}\left(\mathrm{t}^{\prime} \subset \mathrm{t} \rightarrow \operatorname{AGAIN} \operatorname{dial}(\mathrm{x}, \mathrm{y}) \text { at } \mathrm{t}^{\prime}\right) \\
& \text { where } \\
& \text { AGAIN dial }(x, y) \text { at } t^{\prime}=1 \text { iff } \\
& \operatorname{dial}(x, y) \text { at } t^{\prime}=1 \text { and } \operatorname{AGAIN~dial}(x, y) \text { at } t^{\prime} \text { is defined } \\
& \operatorname{AGAIN} \text { dial( } x, y) \text { at t' is defined iff } \exists t^{\prime \prime}\left(\operatorname{MAX}(\lambda t \operatorname{dial}(x, y) \text { at } t)\left(t^{\prime \prime}\right) \wedge t^{\prime \prime}<t\right. \text {, } \\
& \text { and } \exists \text { t"' }(\mathrm{t} \text { " }<\mathrm{t} \text { "' }<\mathrm{t} \text { ' } \wedge \neg \text { dial }(\mathrm{x}, \mathrm{y}) \text { at t"')) }
\end{aligned}
$$

Note that unlike in the translation of the semantically incorporating verb dial in (46), in (48) it is the AGAIN operator itself which is starred. This captures the interpretation of dial as dial something again and again and again ..., which is the interpretation of dial in (42), as shown in (42'). ${ }^{11}$ 
(42') Sam dialed a wrong number for an hour

$\Rightarrow \quad \exists \mathrm{t}[1-\operatorname{hour}(\mathrm{t}) \wedge$ wrong-number $(\mathrm{y}) \wedge \operatorname{AGAIN} * \operatorname{dial}(\mathrm{y}, \mathrm{s})$ at $\mathrm{t}]$

$\equiv \exists \mathrm{t}\left[\mathbf{1 - h o u r}(\mathrm{t}) \wedge\right.$ wrong-number $(\mathrm{y}) \wedge \forall \mathrm{t}^{\prime}\left(\mathrm{t}^{\prime} \subset \mathrm{t} \rightarrow\right.$ $\exists t^{\prime \prime}\left(\operatorname{dial}(s, y)\right.$ at t' $\wedge \operatorname{MAX}(\lambda t \operatorname{dial}(s, y)$ at $t)\left(t^{\prime \prime}\right) \wedge t^{\prime \prime}<t^{\prime} \wedge$ $\exists \mathrm{t}$ "'(t" $<\mathrm{t}$ "' $<\mathrm{t}$ ' $\wedge \neg \operatorname{dial}(\mathrm{s}, \mathrm{y})$ at $\mathrm{t} " \prime)))]$

It follows automatically that (43) lacks an iterative strong interpretation: Wrong numbers denotes a property and cannot combine with the nonincorporating verb in (48), which contains the source of the iterative strong interpretation.

For the odd iterative strong interpretation of (44), the nonincorporating verb (49) is used. The oddness results from the fact that applying AGAIN* to discover does not make much sense: An object can be discovered only once.

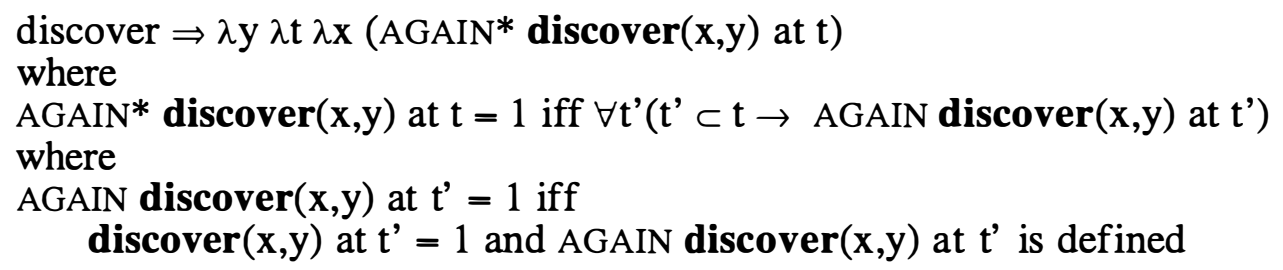

Like (43), (45) lacks an (odd) iterative strong interpretation since in existential contexts the bare plural fleas can only denote a property. Hence, it cannot combine with a nonincorporating verb like (49).

From this excursion into the domain of for-adverbials and silent iterativity, I draw two conclusions. One is that if a semantically incorporating verb is interpreted in an iterative way it can only apply to the property denoted by a bare plural since only the latter's denotation is distributable over event times. The second conclusion is that we can stick to a uniform property-based account of the narrow scope readings of the indefinite in (38) and of the bare plural in (39).

\section{Evidence for a uniform narrow scope account}

What I have shown sofar is that the objections Chierchia (1998) raises to a property analysis can be answered. What I will do now is show that a property analysis allows for a uniform account of (inherent) narrow scope phenomena while a generalized kinds approach does not allow for this. For this purpose, I go through three points. First, the point that inherent narrow scope does not only hold of the English bare plural. Second, we take a look at how Dutch children interpret singular indefinites. And third, I discuss bare plurals like pieces from that puzzle.

\subsection{Inherent narrow scope}

Chierchia argues that in English a singular indefinite and the bare plural have different interpretations. This leaves us with a semantic component which has two separate devices to account for the narrow scope readings of (38) and (39), repeated once more as (50) and (51). 
Sam didn't buy a horse.

i. "It is not the case that Sam bought any horse."

ii. "There was a horse such that Sam did not buy it."

Sam didn't buy horses.

i. "It is not the case that Sam bought any horses."

ii. \# "There were some horses such that Sam did not buy them."

$(<s,<e, \downarrow>)$

On the one hand, we have a quantificational account for the narrow reading of the singular indefinite $a$ horse in (50) and a kind-based account for the inherent narrow reading of the bare plural horses in (51), on the other. This in itself may not be a problem. However, if we adopt a neo-Carlsonian account of the inherent narrow scope of the English bare plural, this means that we need yet another device to account for the inherent narrow scope of those expressions which cannot be said to denote kinds. As Bittner (1994) points out for Inuit, incorporated nouns and their external modifiers have only a narrow scope interpretation, as shown in (52), an example borrowed from Bittner (1994). It would be rather awkward to say that the elements marlunnik and allagar denote the kind "two letters".
Juuna Kaali-mit
marlun-nik allagar-si-nngi-l-a-q.
J.ABS K.-ABL
two-INST.PL letter-get-NEG-IND-[-tr]-3SG
i. "It is not the case that Juuna got two letters from Kaali."
ii. \# "There were a two letters from Kaali and Juuna did not get them."

That a numeral-noun combination cannot be said to denote a kind can be concluded from the fact that such combinations cannot be the subject of a kind-level predicate. ${ }^{12}$ This is illustrated for English in (53) and (54).

? Two lions (vs. lions) are widespread.

(54) ? Three whiskey bottles (vs. whiskey bottles) come in two sizes.

It follows that whatever account one develops to deal with the inherent narrowness of cases like the Inuit one in (52) it cannot be a kind-based account. In a propertybased account, we have not only a uniform narrow scope account of (50) and (51). If a nominal expression in existential contexts is inherently property-denoting, like the English bare plural in (51) is and the Inuit numeral-incorporated-noun combination in (52) is too, its inherent narrow scope follows automatically because such an expression will combine only with a semantically incorporating verb.

\subsection{The acquisition of Dutch indefinites}

The reading paraphrases under (55) indicate that Dutch adults interpret a scrambled indefinite as a wide scope expression.

De jongen heeft een vis niet gevangen.
the boy

i. \# "It is not the case that the boy caught any fish." (\# $\exists$ )

ii. "There was a fish such that it is not the case that the boy caught it." $(\exists \neg)$

Krämer (2000) has found out that more than $80 \%$ of the Dutch children (age 4;0 $5 ; 6$ ) she investigated, interpret scrambled indefinites in a nonadultlike way, that is, as narrow scope indefinites. In Dutch child language, singular indefinites thus 
seem to be interpreted as adult bare plurals, that is, with a strong tendency for an inherent narrow scope interpretation. In a neo-Carlsonian approach, children's indefinites and bare plurals cannot be a natural class in the children's grammar since in adult grammar they have completely separate denotations. In contrast, in a property-based approach, children's indefinites and bare plurals simply build a natural class. They both denote properties. What Dutch children apparently do at some stage in their acquisition of the meanings of indefinites is to overgeneralize their predicative interpretations.

The extent to which this acquisitional argument has crosslinguistic force still needs to be investigated. For instance, the fact that Inuit children acquire noun incorporation at an early stage of their development may indicate that the predicative interpretation of a nominal expression is acquired early. ${ }^{13} \mathrm{~A}$ more reliable answer to the question of whether Inuit children first acquire and therefore overgeneralize the predicative interpretation of indefinites could be found by investigating whether Inuit children interpret those structures in a narrow way too, which typically trigger wide scope readings in adult Inuit. An interesting test would be to check whether Inuit children interpret the object NPs in transitive constructions, which are structures that trigger wide scope in Inuit adult language, as predicative indefinites. An example is given in (56).
Jaaku-p
umiarsuaq
taku-sima-nngi-l-a-a.
ship.ABS
see-PERF-NEG-IND-[+tr]-3SG.3SG
i. \# "It is not the case that Jacob saw a ship."
ii. "There was a ship such that Jacob did not see it."
[Bittner (1988): 43]
$(\# \neg \exists)$
$(\exists \neg)$

\subsection{Pieces from that puzzle}

In this section, I turn to one type of the English bare plural which never denotes a kind. Examples of these NPs you find under (57).
a. parts for that machine
b. parts from the airplane
c. pieces from that puzzle

As Carlson (1977) points out, these bare plurals never denote a kind but they nevertheless may exhibit the same "differentiated scope" behaviour as regular bare plurals (see Carlson (1977): 318). While (58) has only an absurd omnipresent reading of the indefinite $a$ part from the airplane, the bare plurals parts from the airplane in (59) and airplanes in (60) have only a distributive reading.

(58) A part from the airplane was everywhere.

(59) Parts from the airplane were everywhere.

(60) Airplanes were everywhere.

Similarly, while the sentences (61) and (62) with the indefinites a piece from that puzzle and $a$ book that I lost yesterday only receive a crazy iterative reading, the sentences (63) and (64) with the bare plurals pieces from that puzzle and books that I lost yesterday do not sound crazy. They are just as fine as the sentences (65) and (66) which contain the regular bare plurals puzzles and books.

(61) ? Max discovered a piece from that puzzle for three hours.

(62) ? Fred repeatedly destroyed a book that I lost yesterday. 
(63) Max discovered pieces from that puzzle for three hours.

(64) Fred repeatedly destroyed books that I lost yesterday.

(65) Max discovered puzzles for three hours.

(66) Fred repeatedly destroyed books.

Still, according to Chierchia (1998) bare plurals like parts for that machine are indefinite NPs. For him this correctly predicts that the NP parts for that machine in (67) receives a narrow and a wide interpretation.

John didn't find parts for that machine.

i. "It is not the case that John found any parts for that machine."

ii. "There were some parts for that machine such that John did not find them."

However, assigning the wide scope reading to (67) is problematic for at least four reasons. First, what happens to Carlson's observations with respect to the contrast between (58) and (59), and between (61)-(62) and (63)-(64)? That is, if the notkind-denoting bare plurals in (59), (63), and (64) should be really interpreted as indefinites, why do these bare plurals not pattern with their singular indefinite counterparts in (58), (61), and (62)? That is a piece from a puzzle which Chierchia does not solve.

Second, to contrast indefinites with regular bare plurals Carlson (1977) presents the contradictory reading test. We see that this test applies here too. While (68) can have a noncontradictory reading, (69) cannot. In other words, if a store owner tells you (69), you may get slightly irritated after you have shown him your lamp.

(68) Some light bulbs for this lamp are for sale here and some light bulbs for this lamp are not for sale here.

(69) Light bulbs for this lamp are for sale here and light bulbs for this lamp are not for sale here.

Still, some not-kind-denoting bare plurals seem not to give rise to this kind of irritation. For some speakers of English (70) is a case in point.

(70) Parts of that machine have been found now and parts of that machine have not been found now.

Does this mean that sentences like (67) have a wide scope reading after all? I believe not. The reason why (70) seems to escape a contradictory reading lies in the meaning of parts of. A machine usually consists of many different parts. Suppose after an accident some firemen are collecting the parts of a machine that exploded, and they say (70) to a policeman who wants to know what is going on. In that case, the policemen will believe that the firemen are cooperative and do not want to fool him when they say (70). The apparently specific interpretation of parts of that machine as some parts of that machine arises because the policemen realizes that the firemen have not yet found all the parts. Still, this specific reading must be a pragmatic effect triggered by parts of since otherwise (71) should have a reading in which parts of that machine is understood as an omnipresent set of parts. But there is no such reading for (71).

(71) Parts of that machine were everywhere. 
Third, in German not-kind-denoting and regular bare plurals pattern alike in the sense that they both cannot scramble. This is illustrated in (72) and (73).

$$
\text { * Jan hat Birnen für diese Lampe nicht gefunden. }
$$
J. has bulbs for this lamp not found * Jan hat Bimen nicht gefunden.

As shown in (74) German indefinites can scramble. In fact, they must scramble to receive a specific interpretation.

Jan hat $\quad$ einige Birmen für diese Lampe nicht gefunden.
J. has $\quad$ some bulbs for this lamp

To my knowledge, German bare plurals and English bare plurals have the same semantic behaviour. On a Chierchian account of not-kind-denoting bare plurals it would be unclear why the German counterpart of light bulbs for this lamp cannot scramble, that is, why in (72) this NP cannot be understood as a specific indefinite.

Finally, if not-kind-denoting bare plurals were like indefinites, we would predict that like (75), (76) is well-formed. But it is not. A not-kind-denoting bare plural cannot be the subject of an individual-level predicate.

Some dogs are intelligent.

* Dogs in the next cage are intelligent.

On a property approach, the narrow scope behaviour of not-kind-denoting bare plurals is not a surprise. They denote properties from which no natural kind can be created. Note that they nevertheless denote properties which hold of singularities and of pluralities. As such they are temporally distributable which means that they can be semantically incorporated by a silently iterative verb such as discover in (63). Note in this respect that they are also distributable over space, which allows them to combine with the predicate be everywhere without yielding an omnipresent reading, as shown in (59) and (71). ${ }^{14}$

\section{Conclusion}

Let me summarize what I have accomplished here. First, I have answered the objections that Ghierchia raises against an account which allows for property arguments. In this respect, I have shown that there is no need for a deep semantic explanation for why English has no bare count singulars. I have also shown that reflexive kind anaphora can be treated in a property-based account of the English bare plural. And I have shown that the scopelessness of the English bare plural does not raise problems for a property analysis. On the contrary. I have shown that the successful interaction of indefinites with for-adverbials depends on whether we can interpret the verb in an iterative way or not, or on whether there is an overt iterative adverbial or not. Finally, and more importantly, I have shown that a property analysis can account uniformly for a wide range of (inherent) narrow scope phenomena. However, a neo-Carlsonian account cannot. 


\section{Endnotes}

* For their comments and criticisms I thank Greg Carlson, Irene Heim, Wolfgang Klein, Louise McNally, and Sandro Zucchi.

1. Following this view, Van Geenhoven and McNally (2000) understand opacity as a special case of nonspecificity. That is, opaque arguments are interpreted as modally embedded properties. This is illustrated in (i) for look for.

(i) $\quad \forall \mathrm{x} \forall \mathrm{P} \forall \mathrm{w} \square\left(\right.$ look-for $_{\mathrm{w}}(\mathrm{x}, \mathrm{P}) \leftrightarrow \operatorname{try}_{\mathrm{w}}\left(\mathrm{x}, \lambda \mathrm{w}^{\prime} \exists \mathrm{y}\left[\right.\right.$ find $\left.\left.\left._{\mathrm{w}^{\prime}}(\mathrm{x}, \mathrm{y}) \wedge \mathrm{P}_{\mathrm{w}^{\prime}}(\mathrm{y})\right]\right)\right)$

2. Following Van Geenhoven (1998), I assume that the singular indefinite is ambiguous between a property and a free variable interpretation. On the latter interpretation it receives its quantificational force through accommodation, which is the mechanism that takes care of the non-narrow readings of indefinites.

3. I adopt Chierchia's notation and represent characteristic functions by enclosing their extension in square brackets.

4. L. McNally points out that despite the ungrammaticality of (21) English has a number of bare singulars (e.g. go by train/car, eat dinner/lunch, etc.).

5. See Hinrichs (1985): 295-301 for the same observation.

6 . Note that $-q$ on qimme - is not an absolutive case marker but rather a number marker for singularity. Absolutive case is not overtly realized in Inuit.

7. In contrast to Chierchia, I assume that the cap operator creates kinds out of properties that simultaneously hold of singularities and of pluralities. I suggest that it is also this operator which becomes active if a bare plural occurs in a generic context, and which turns the bare plural's basic property meaning into that of a kind. In this paper, I do not discuss the interpretation of bare plurals in generic contexts.

8. In Van Geenhoven (2000), I show that one of the disadvantages of Krifka's approach is that iterativity is reduced to nonquantization. For example, the fact that (i) can have two readings, namely what I call a nonstop reading and what I call an iterative reading, is not visible in a semantic representation that is based upon the fact that discover fleas is nonquantized.

(i) Bill discovered fleas on his dog for an hour.

a. "Bill discovered fleas nonstop for an hour." nonstop

b. "Bill discovered fleas again and again for an hour." iterative

The fact that the iterative one is the more natural reading of (i) is simply ignored and reduced to the fact that discover fleas is nonquantized.

9. The idea that if no overt iterative expression is present, iterativity must be expressed on the verb could also be captured by saying that the verb must express pluractionality (see Lasersohn (1995)).

10. Unlike Lasersohn (1995), I do not start out with a basic meaning of pluractionality to which then clauses are added that deal with the different readings of pluractionality (see Lasersohn's "continuous" and "separated" readings). The way in which these different readings come about in my approach depends on whether the verb is semantically incorporating or not, on whether the * and AGAIN operator are both present or not, and on how the verb, ${ }^{*}$, and AGAIN interact with each other.

11. Note that in (42') the variable $y$ introduced by the indefinite $a$ wrong number is free. We need an additional interpretive mechanism to bind this variable (see Abusch (1994), Van Geenhoven (1998)).

12. G. Carlson points out to me that unlike the numeral-noun combinations some numeral NPs seem to be fine as the subject of a kind-level predicate. His examples are the following:

(i) Pairs of lions (vs. two lions) are very common.

(ii) Octuplets (vs. eight siblings born at the same time) are usually dressed alike. 
According to him these data seem to undercut the initial implausibility of my claim that numeral-noun combinations cannot denote a kind.

13. See Fortescue and Lennert Olsen (1992) for the early acquisition of noun incorporation in West Greenlandic Inuit, and Allen (1996) for the early acquisition of noun incorporation in Inuktitut, a variety of Inuit spoken in Canada.

14. To account for the fact that a singular indefinite gives rise only to an odd and omnipresent reading I suggest that the predicate be everywhere is "pluractional" in the sense that it combines only with complements that denote spatially distributable properties.

\section{References}

Abusch, D. (1994) The Scope of Indefinites. Natural Language Semantics 2, 83135.

Allen, S. (1996) Aspects of argument structure acquisition in Inuktitut. Amsterdam: Benjamins.

Bittner, M. (1988) Canonical and noncanonical argument expressions. Ph.D. Diss., UT, Austin.

Bittner, M. (1994) Case, Scope, and Binding. Dordrecht: Kluwer.

Carlson, G. (1977) Reference to Kinds in English. Ph.D. Diss., UMass, Amherst. Published (1980). New York: Garland.

Chierchia, G. (1998) Reference to Kinds across Languages. Natural Language Semantics 6, 339-405.

Fortescue, M. and L. Lennert Olsen (1992) The Acquisition of West Greenlandic. In D. Slobin (ed.) The cross-linguistic study of language acquisition, Vol. 3, 111-220. Hillsdale, NJ : Erlbaum

Hinrichs, E. (1985) A Compositional Semantics for Aktionsarten and NP Reference in English. Ph.D. Diss., OSU, Columbus.

Krämer, I. (2000) Interpreting indefinites: an experimental study of children's language comprehension. PhD. Diss., Universiteit Utrecht.

Krifka, M. (1989) Nominal reference, temporal constitution, and quantification in event semantics. In R. Bartsch et al. (eds.) Semantics and Contextual Expressions, 75-115. Dordrecht: Foris.

Krifka, M. et al. (1995) Genericity, an Introduction. In G. Carlson and F. Pelletier (eds.) The Generic Book, 1-124. Chicago: UCP.

Lasersohn, P. (1995) Plurality, Conjunction, and Events. Dordrecht: Kluwer.

Link, G. (1983) The logical analysis of plurals and mass terms: a lattice-theoretic approach.In R. Bäuerle et al. (eds.) Meaning, Use, and Interpretation, 302323. Berlin: Mouton.

McNally, L. (1992) A semantics of the English existential construction. Ph.D. Diss., UCSC. Published (1997). New York: Garland.

Partee, B. (1987) Noun Phrase Interpretation and Type-Shifting Principles. In J. Groenendijk et al. (eds.) Studies in Discourse Representation Theory and the Theory of Generalized Quantifiers, 115-143. Dordrecht: Foris.

Van Geenhoven, V. (1998) Semantic Incorporation and Indefinite Descriptions. Stanford: CSLI Publications.

Van Geenhoven, V. (2000) On durativity and iterativity: the case of for-adverbials. Ms. MPI, Nijmegen.

Van Geenhoven, V. and L. McNally (2000) Beliefs about opaque and other property arguments. Ms. MPI, Nijmegen/UPF, Barcelona.

Williams, E. (1983) Semantic vs. Syntactic Categories. Linguistics and Philosophy $6,423-446$. 
Zimmermann, T. E. (1993) On the Proper Treatment of Opacity in Certain Verbs. Natural Language Semantics 1, 149-179.

Zucchi, A. and M. White (1996) Twigs, sequences and the temporal constitution of predicates. In T. Galloway and J. Spence (eds.) Proceedings of SALT VI, 337-354. Ithaca: CLC Publications. 